\title{
Aisthesis
}

Firenze University Press

www.fupress.com/aisthesis

OPEN ACCESS

Citation:O. Kiianlinna(2021)Contradiction That Never Was: Epigenesis versus Modularity in Evolutionary Aesthetics. Aisthesis 14(2): 79-91. doi: 10.36253/Aisthesis-13054

Copyright: (c) 2021 O. Kiianlinna. This is an open access, peer-reviewed article published by Firenze University Press (http://www.fupress.com/aisthesis) and distributed under the terms of the Creative Commons Attribution License, which permits unrestricted use, distribution, and reproduction in any medium, provided the original author and source are credited.

Data Availability Statement: All relevant data are within the paper and its Supporting Information files.

Competing Interests: The authors have declared that no competing interests exist.

\section{Contradiction That Never Was: Epigenesis versus Modularity in Evolutionary Aesthetics ${ }^{1}$}

\author{
Onerva Kitanlinna \\ University of Helsinki (Finland) \\ onerva.kiianlinna@helsinki.fi
}

\begin{abstract}
Coevolutionary aesthetics has been forming since the early 2010s. Its contribution of great value has been the inclusion of cultural evolution into Darwinian theories on the origins of art and aesthetic judgement. Coevolutionary aesthetics - or nonmodular evolutionary aesthetics as it is sometimes called - emphasizes that aesthetic behavior develops in a specific social environment. Coevolutionary aesthetics suggests that traditional evolutionary aesthetics, drawing from evolutionary psychology, has ignored this. The critical position stems from the widely accepted notions that humans adapt plastically to changing conditions and that there is no «innate» aesthetic module in the mind. What has not been examined is that modularity itself is often considered a condition for plasticity of mind. My main argument is that aesthetic inference is a metarepresentational module without direct fitness-increasing functions. Coevolutionary and evolutionary psychological aesthetics are thus more complementary than contradictory. Combining modular and coevolutionary thinking is the most consilient way forward in evolutionary aesthetics.
\end{abstract}

Keywords: Aesthetic judgement, Cognitive gadgets, Coevolutionary aesthetics, Modu- larity of mind, Metarepresentational modules.

\section{INTRODUCTION}

Positioning human cognitive and sensory systems in a continuum with those of other animals, it seems intuitive that evolution amongst other factors - affects the way we arrive at aesthetic judgements, such as «this rose is beautiful». However, there is no consensus on what the impact of evolution exactly means in the case of aesthetic judgements.

The most recent debate concerns how the capability for making aesthetic judgements forms for an individual, and how it is inher-

\footnotetext{
${ }^{1}$ I weave my article into the terminology and discourse of coevolutionary aesthetics by using the term «epigenesis». Here, it refers to environmental factors other than DNA affecting our behavior. It does not directly refer to epigenetics, a field of biology studying the regulation of DNA sequences.
} 
ited without there being «innate» predispositions that are specific for aesthetic behavior. Several scholars have presumed for some while that no single evolutionary adaptation is necessary or sufficient for all instances of aesthetic judgement (Pitkänen [2009]: 18; Chatterjee [2014]; Richards [2019]: 24-29)2. Aesthetic behavior may well be a nonadaptive by-product or a collection of different adaptations and exaptations to various environmental conditions, which together with cultural transmission and niche construction enable aesthetic judgement ${ }^{3}$. The scope of coevolutionary aesthetics is to explore this process.

The shared reasoning behind the various arguments in coevolutionary aesthetics goes roughly along the following lines: many kinds of components affect human behavior, some of which we can explain with natural selection and some of which we cannot, but most of which overlap and merge. This can be easily agreed with, and I support Mariagrazia Portera and Mauro Mandrioli (Portera, Mandrioli [2015]: 60-61), who, speaking in favor of overcoming dichotomies like «nature/ culture, universalism/relativism, and objectivism/ subjectivism», summarize a stand that I believe can be adopted by all in the field of coevolutionary aesthetics. Although I agree with the general plea for non-modular evolutionary aesthet-

\footnotetext{
${ }^{2}$ Adaptations are traits an organism - or, more specifically, a phenotype - manifests that have been preserved in natural or sexual selection due to a positive fitness value they provide their bearer with over several generations. Positive fitness value refers to better likelihood of survival of the DNA, compared to the DNA of individuals without the trait.

${ }^{3}$ Exaptations are: a) by-products of adaptations, i.e., traits that do not increase fitness, so that it would explain that the trait endures, and b) secondary adaptations, i.e., traits that have been preserved in natural or sexual selection due to a positive fitness value they provide their bearer with, but have after several generations begun to serve a different evolutionary function that also increases the bearer's fitness, which now explains that the trait endures. Niche construction means that the actions of an organism form its environment so that rather than adapting to pre-existing environmental conditions, it participates in creating its own ecological niche.
}

ics defined as moving away from constructing a strictly adaptationist hypothesis for existing categories of aesthetic behavior, I maintain some reservations.

Before theorizing on the evolutionary history of aesthetic behavior, it is important to clarify what the evolving entity is thought to be. Much effort in coevolutionary aesthetics has been directed at expanding on how there is not an «innate» aesthetic module in the mind with a consistent evolutionary history. Coevolutionary aesthetics positions itself against previous claims that our aesthetic behavior could serve some evolutionary function or be a by-product of such behavior. What has been left out is that the human mind is most likely modular, according to the massive modularity hypothesis from evolutionary psychology ${ }^{4}$. This is so even when there is probably not a specific aesthetic adaptation or instinct.

${ }^{4}$ By «modularity», I do not refer to Jerry Fodor's original thoughts from 1983 but to massive modularity (see, for example, Carruthers [2006]: 1-7). In the latter, modularity means functional specialization instead of a more automatic and rigid system (Barrett, Kurzban [2006]: 629-630). «Fodor-modules» demonstrate domain specificity, mandatory operation, limited central accessibility, fast processing, informational encapsulation, «shallow» outputs, fixed neural architecture, characteristic and specific breakdown patterns, and lastly, characteristic ontogenetic pace and sequencing. Modules in massive modularity, or "Carruthers-modules», in turn, indicate dissociability, weak neural localizability, and central inaccessibility (Robbins [2017]). Besides neatly contrasting the two, Philip Robbins (2017) shows that the concept of module in massive modularity is not only much weaker but that at the same time mind is seen as modular throughout the central systems. In addition to Fodorian narrow-scope information encapsulation, wide-scope encapsulation allows the system at work to utilize some outside information: «the hypothesis at issue for theorists like Carruthers might be best understood as the conjunction of two claims: first, that input systems are modular in a way that requires narrow-scope encapsulation; second, that central systems are modular, but only in a way that does not require this feature» (Robbins [2017]). Modules do not have to be domain-specific, because the subject matter the module can process, its domain, can be flexible while the module's internal operations can be somewhat independent from other systems (Carruthers [2006]: 5). 
Massive modularity is a controversial idea and has both advocates and opponents. Even though more research is no doubt needed to settle the debate, I am using it here as a working hypothesis since I have understood it is so far the best explanation for plasticity (Mercier, Sperber [2017]: 74). I rely on Hugo Mercier and Dan Sperber's conception of a module rather than using it as a synonym for adaptation ${ }^{5}$.

Module means a functional mechanism - such as an anatomical or behavioral trait - with the ability to process certain input in certain environments. It can consist of sub-modules, it can be a sub-module itself, and it can be a part of a group of modules that, in turn, forms a module. Modules do not necessarily have to be products of natural selection, but they can have culturally evolved functions. According to Mercier and Sperber, alongside many others, the modularity of complex organisms is a necessary condition for adaptive flexibility, because modularity allows organisms to plastically actualize different modules and their combinations in different environments (Mercier, Sperber [2017]: 73-75). This is so even if the mentioned flexibility is not a sufficient evolutionary explanation for why modularity evolves (Clune, Mouret, Lipson [2013]: 1).

The main claims of this article are threefold: First, I claim that a common premise in evolutionary aesthetics has been that the aesthetic way of inference is an independent entity, a phenomenon whose operating principles cannot be reduced to some more general or any other phenomenon. Second, I claim that evolutionary aesthetics could benefit by better articulating its relation to modularity rather than blacklisting the word and founding a totally unmodular evolutionary aesthetics, which, I suggest, is an oxymoron ${ }^{6}$. Third, I claim

\footnotetext{
${ }^{5}$ Jonathan Kramnick (2011): 321-322 criticizes literary Darwinism for utilizing the conception that a module answers for an adaptation.

${ }^{6}$ For example, Fabrizio Desideri advocates abandoning modularity in favor of plasticity: «As an alternative, I suggest that the human mind should be rather defined, from a species-specific perspective, appealing to the emergence of the aesthetic as an unmodular device, a device, that is
}

that the mechanism for aesthetic judging can be treated as a metarepresentational module with a possible selectionist history. This means reconceptualizing coevolutionary aesthetics as explicitly utilizing evolutionary psychology. Finally, I briefly explore what strands my argumentation opens up for future research in evolutionary aesthetics.

\section{CAPACITY FOR AESTHETIC JUDGEMENT AND ITS EVOLUTION}

One of the largest common denominators in evolutionary aesthetics is that there is such an entity as an aesthetic way of inference, aesthetic judgement, or taste ${ }^{7}$. Theorizing often starts from the notion that aesthetic judgement is the object of inquiry, as Eveline Seghers describes: «Evolutionary aesthetics attempts to explain the human ability to perceive objects, conspecifics and the surrounding environment in an aesthetic manner - i.e. in an emotional and evaluative way resulting in a positive or negative appraisal - by referring to the evolutionary history of our functional, cognitive make-up» (Seghers [2015b]: 73) ${ }^{8}$.

Although aesthetics as a coherent academic discipline is not an old idea, the conception of aesthetic perception as a coherent whole sits tight in evolutionary aesthetics - even when the aim is not to argue for its coherent evolutionary history

not tied to perceptual modules and rigidly defined functions, but is characterized by degrees of freedom and by a native and indeterminate plasticity» (Desideri [2013]: paragraph 20).

${ }^{7}$ While evocriticism can be seen as a part of evolutionary aesthetics, it does not have to take a stance on the matter. ${ }^{8}$ Sometimes the scope is more restricted: for example, Stephen Davies only includes judgements concerning beauty, sublime and their counterparts (Davies [2012]: chapter 1). I refrain from the analytical aesthetics' discussion concerning cognitive and emotional aspects of aesthetic judgements. For the purposes of this article, a general statement that emotions are part of cognitive processes suffices. See, for example, Chatterjee and Vartanian (2014): 370-371 for an account of sensory-motor, emotion-valuation, and meaning-knowledge neural systems at play in aesthetic judgement. 
(see, for example, Dutton [2009]: 206; Schellekens [2011]; Davies [2020]: 70). This is characteristic for the philosophical discussion in evolutionary aesthetics and also many empirical experiments in cognitive aesthetics and neuroaesthetics. For example, the possibility of humans and chimpanzees sharing a similar "aesthetic sense» is sometimes used as grounds for the argument that further comparative studies are worthwhile to shed light on the evolutionary history of the human trait of making aesthetic judgements (Seghers [2014]: 270-271).

Could evolutionary aesthetics' underlying view on one aesthetic inference ${ }^{9}$ - in Seghers's words, «an emotional and evaluative way resulting in a positive or negative appraisal» - be false? Inspiration for such skepticism can be found in empirical aesthetics. Martin Skov and Marcos Nadal suggest that the idea of psychologically or neurobiologically specific and special aesthetic experiential states - for example, aesthetic emotions as a different group from other types of emotions - is an unfounded assumption (Skov, Nadal [2019]: 2). Having said this, universality of the appearance of aesthetic objects, and hence aesthetic judgements, has often been articulated during the course of evolutionary aesthetics (for example, Deacon [2006]: 22; Malotki, Dissanayake [2018]: 47; Davies [2020]); therefore, it is understandable, and even advisable, that scholars start speculating why this is so. However, is there any reason to assume common evolutionary history of a skill behind all aesthetic judgements, even if it had little to do with natural selection?

Elisabeth Schellekens (2011) points out the common, and justified, concern that in empirical

\footnotetext{
${ }^{9}$ By «aesthetic inference», I refer to the process of forming aesthetic judgements in humans. The reason I use these somewhat overlapping two terms is that my argumentation relies on cognitive science and evolutionary psychology. Mercier and Sperber (2017): 53-54, 59, adopt the wide Humean definition of «inference» as «[...] extraction of new information from information already available, whatever the process» that can be deliberate, automatic, or anything in-between and that is typical for all cognitive systems.
}

studies, aesthetics' concepts can be used carelessly, even leaving their core aspects out. The same plea for conceptual openness also applies to the way philosophers use their own concepts and construct new ones in evolutionary aesthetics. When studying universal aesthetic judgements, scholars rely on both the concepts and epistemologies from the contemporary framework for academic thought. This distorts imagining different possibilities and might already steer the scholars away from how the human mind has evolved (Dissanayake [2018]: 116). One such distortion could be the very notion of aesthetic judgement, and the conception that its mechanism is uniform in all cases grouped as aesthetic.

Scratching beneath the surface, what exactly is being explained in evolutionary aesthetics seems hard to reduce to necessary and sufficient conditions. Alongside singular aesthetic judgements that come and go, examination focuses on the potentiality of them as a universal human trait. I follow Schellekens (2011) and speak about aesthetic judgements rather than aesthetic experiences, because aesthetic experiences can be even harder to define accurately. I do not deny the existence or relevance of aesthetic experience in our inner worlds per se but here leave the concept out for the sake of clarity. I see aesthetic judgements as a way of inference, similarly as Mercier and Sperber see reasoning as one way of inference. According to Mercier and Sperber, justifications follow a conclusion in the process of reasoning (Mercier, Sperber [2017]: 125-126). It resembles aesthetic judgements in that experience comes first, followed by a judgement. I will return to this process later in this article.

The capacity for aesthetic judgements, aesthetic sensibility, should not be seen as a static trait of the subject disconnected from environmental impact. Evolutionary aesthetics does not concern an individual mind or its capacity to take in sensory input at the expense of the aesthetic object. Rather, the objective of evolutionary aesthetics depends on both environment - including the social one - and the subject as an interactive mesh (for a similar account, see Desideri [2015]: 35). It 
does not get us far to ponder if we should explain mind or aesthetic cultures as behavior, either. Their interaction has become so evident that by virtue of its office, aesthetic inference with accompanying metacognitive intuitions are evolutionary aesthetics' sphere ${ }^{10}$. Aesthetic judgement as a product of aesthetic inference is not computing and conserving the surroundings "as they are», but inherently involves interpreting and creating meanings, without the judging being either automatic or deliberate. How this mechanism emerges for each individual is largely shaped by culture.

Hence, I fully endorse the program to incorporate more factors into evolutionary aesthetics by coevolutionary aesthetics. Coevolutionary aesthetics adopts a plea for epistemic modesty as it broadens the explanatory frameworks from adaptationist thinking. It argues for a more holistic in my reading, more consilient - approach, as it hopes to include knowledge not only from natural sciences to aesthetics but also from analogies and humanities in evolutionary hypotheses. In addition to the existing outline, theories on cultural transmission and social learning strategies will complement the move to coevolutionary aesthetics (Verpooten, Dewitte [2017]: 20-21; Kiianlinna [2018]: 62-68; Bartalesi [2019]). At the same time, I remain reserved toward the rhetoric that this would or should be a turn away from evolutionary psychology, as coevolutionary aesthetics often positions itself. For example, Portera and Bartalesi position themselves against evolutionary psychology in evolutionary aesthetics by opposing a strong innateness of aesthetic cognition and appealing to the uselessness of the nature/nurture dichotomy: "We will argue that the EP and EA way of understanding the relationship between nature and culture - nature being innate and universal and culture being acquired, local, and contingent - is not the best way to try to explain the

\footnotetext{
${ }^{10}$ Mercier and Sperber define intuitions, or intuitive inference, as «[...] the output of a great variety of inferential modules, the output of which is to some degree conscious while their operations remain unconscious» (Mercier and Sperber [2017]: 133).
}

development of aesthetic preferences» (Portera, Bartalesi [2016]: 380).

Portera and Bartalesi highlight the dichotomy evolutionary psychology versus environmental impact. Although I agree with that there is a good reason to move on from and enrichen strictly nativist views in evolutionary aesthetics ${ }^{11}$, I find that Portera and Bartalesi paint an unnecessarily divaricate caricature of the mainstream evolutionary aesthetics scholars by stating they value adaptations higher than anything else affecting an aesthetic judgement:

evolutionary psychologists - whose perspective currently prevails within the field of evolutionary aesthetics - conceive sexual and environmental preferences as innate, universal and species-specific, a sort of «universal basement» compared to which cultural differences are no more than superficial accidents. (Portera, Bartalesi [2016]: 384)

I take up a counterexample from a major branch of evolutionary aesthetics focusing on storytelling. According to literary Darwinist Joseph Carroll, claiming that evolutionary psychology ignores anything else but adaptations is an unhappy misunderstanding, which requires constructing an erroneous view that learnt behavior and evolutionarily adaptive behavior could be separated from each other (Carroll [2012]: 408). «Nature» and "nurture» are not separate from each other, despite the common language dichotomy Portera and Bartalesi refer to as an erroneous basis of evolutionary aesthetics. Learning and learnt things are necessarily part of evolutionary thinking. There is no measure that allows comparing if vague «genes» or «environment» are primary for the realization of any behavior or cognitive mechanism, because these are not separable causes (Keller [2010]: 6, 75). All scholars can do is to study different factors influencing the behavior or mechanism in question - in this case, the capacity of forming aesthetic judgements - and at best position it in a continuum based on the level of

${ }^{11}$ Denis Dutton (2009): 206 is an example of a nativist thinker in evolutionary aesthetics. 
its malleability in the course of maturing (Keller [2010]: 82; Mercier, Sperber [2017]: 69).

Evolutionary psychology would be hard to discard, as in many cases it offers explanations for the cognitive systems that affect the way we gather and process inferences (Sperber [2001]: 402). Concerning evolved cognition, an evolutionary aesthetics explanation inevitably touches upon these systems. Learning capabilities produced by evolution are an important factor when explaining our cultural behavior and how culture shapes us: what we can learn, what kinds of things we can transmit culturally, and in what kinds of environments we tend to rely on different learning strategies. Thus, I agree with Seghers, for example, that although the traditional evolutionary psychological studies of art are not only highly partial but often also lacking sufficient empirical evidence, evolutionary psychology itself is valid as an approach (see Seghers [2015a]: 233).

The turn away from evolutionary psychology is justified by pointing out that when it comes to aesthetic judgements, the human mind is most likely not modular in the way evolutionary psychologists claim; there is no aesthetic module (Portera, Mandrioli [2015]: 59). However, the claims concerning modularity are based on different uses of the concept of module. Critics of evolutionary psychology often oppose that there would be a determined art (form) module in the human mind; mind is not constructed like a Swiss army knife, where artistic activity would be but one more corkscrew in the overall package. What is interesting is that the other side seems to agree. As already stated, many contemporary scholars using evolutionary psychology in their research on art actually advocate for the plastic mind prone to adapting to changing environmental conditions rather than consisting of cognitive modules fit for only some singular activity, like artmaking. Some evolutionary psychologists reckon that plasticity of mind in fact results from and therefore relies on modularity (Barrett, Kurzban [2006]: 635; Mercier, Sperber [2017]: 74). In other words, coevolutionary aesthetics seems to be based on modularity in a broad sense insofar as it concerns behavioral dispositions relevant for aesthetics, regardless of whether they are inbred or acquired.

Analyzing the development of all aesthetic preferences that influence and guide our aesthetic judgements is a rigorous task because they do not develop in unison. Some aesthetic preferences are individual, some coincidental, some universal, and some have to do with a unique cultural environment. Most fall into multiple classes at the same time. Factors that play into a specific aesthetic judgement are manifold, as they are not only sensory stimuli or perceptual input; also, an individual's homeostatic needs, expectations, and behavioral concerns shape the output (Skov, Nadal [2019]: 8 ). There is no aesthetic judgement that would be purely biological, purely cultural, purely subjective, or purely objective.

Although we may on average have tendencies for certain kinds of aesthetic reactions, an aesthetic judgement is also affected by other factors. Evolutionary aesthetics has room for mapping out all kinds of factors affecting aesthetic judgements and their universality, diversity, and changing in time. If some of these factors are more directly connected to natural selection than others, this by no means denotes that they are theoretically more important or trivial than the rest. With humans being an ultrasocial species, it would be surprising if a certain kind of aesthetic judgement could only be explained by an evolutionary hypothesis without any support of culturally transmitted values, learnt habits, or historically specific processes. The explanation in evolutionary aesthetics concerns phenotypes, or the way an organism functions in its environment rather than merely its DNA and the proteins DNA codes.

In a nutshell, the omission to acknowledge the wide and contemporary definition of a module leads to puzzling theoretical positions. For Portera (2020): 313 - who positions herself in the same group as Fabrizio Desideri, namely, non-modular evolutionary aesthetics - there seems to exist an aesthetic sense or disposition no matter how diverse and unique its development is. Both claim that there is an aesthetic behavioral disposition and argue for plasticity of this tendency. There- 
fore, although Portera positions herself against modularity, it is upon modularity that she builds her thesis. Desideri in turn, uses the notion of an «aesthetic device», drawing on Terrence Deacon's ideas, and speaks about the "unitary core of our aesthetic experience» (Desideri [2013]: paragraph $20)^{12}$. So, is there an aesthetic module after all?

\section{FORMING AESTHETIC JUDGEMENTS AS A METAREPRESENTATIONAL MODULE}

The traditional category of an underlying aesthetic sense or sensibility seems obscure from an empirical point of view. Neuroaesthetics has illustrated that specifically aesthetic receptors, emotions, and cognition do not exist from the physiological viewpoint, but various neural systems activate flexibly in experiences described as aesthetic (Chatterjee [2014]: 183-184).

Perhaps, then, all aesthetic judgements do not share the same evolutionary aspects, but in the evolutionary sense they might be less related. Here, aesthetic judgement would be treated as a philosophical concept, not a specific inferential mechanism, and explanation would be focused on particular judgements. Rather than talking about an "aesthetic mechanism», "aesthetic sense», or «art instinct» (see, for example, Davies [2020]: 70; Dutton [2009]: 7), evolutionary aesthetics might be better off looking at other - and from the viewpoint of aesthetics, narrower - modules, such as imagination or perceiving symmetry with larger domains than that of aesthetics. The same would apply to more restricted accounts of some behaviors traditionally seen as entities, which does not mean that they would be natural entities from the evolutionary viewpoint.

\footnotetext{
${ }^{12}$ See also Desideri (2015): 35: «[...] we cannot identify the aesthetic mechanism with a particular faculty or a specific function and, even less, we can locate it in a single area of the brain. We have to think, rather, of a blending between different attitudes of dispositional nature. A non-modular device that can synthesize these attitudes in an original and advantageous way, moving from attractors or affordances offered by the environment».
}

In other words, all evolutionary aesthetics could do was to provide knowledge consisting of several significantly smaller contributions to much more specific instances or modules than have traditionally been studied in the field, such as art or aesthetic judgement as an entity. Also, some aesthetic qualities ${ }^{13}$, such as beauty, may be hard to incorporate in evolutionary aesthetics as such. Being used as a very wide description, the possibility that evolutionary theory anachronistically explains something else than beauty as a category increases. Moreover, treating beauty as an evolutionary category and not only a philosophical one may not make sense because different experiences of beauty are processed in different parts of the brain (Chatterjee [2014]: 65-66) ${ }^{14}$.

Focusing on other categories than beauty, one can still embrace the existence of specifically aesthetic behavior (for example, appreciation of beauty) as a human universal; the principal object of inquiry - aesthetic inference - remains. Leaving some core aesthetics concepts without an evolutionary history of their own might save the thinking within evolutionary aesthetics from unnecessarily constructing yet another mental module. If anything, this brings evolutionary aesthetics into closer cooperation with its neighboring fields, including philosophical aesthetics and neuroaesthetics. It opens up the exchange both ways, not

\footnotetext{
${ }^{13}$ For the sake of clarity and curbing the topic at hand, I speak about aesthetic qualities rather than aesthetic value. Many of the references employed use the term «aesthetic value», and therefore it appears in this article. For my purposes, however, it suffices to note that aesthetic qualities often indicate aesthetic value - which differs from artistic value since not all aesthetic judgements concern art, and art can also be judged in other than aesthetic terms - without going into too much detail about the extensive philosophical discussion concerning aesthetic value itself.

${ }^{14}$ However, theorizing about perceiving perennial aesthetic properties would still not be doomed per se, because we use the same cognition for different things. This becomes evident, for example, in Angela Breitenbach's (2020) argumentation for imagination as the same mental activity at play in both perceiving beauty and reaching cognitive understanding.
} 
only borrowing concepts from other fields but also, ideally, contributing to them.

The role of an evolutionary aesthetics explanation would then be to map out already existing modules at play in a given aesthetic judgement, see how they are articulated, and finally form a picture that has been of interest for aesthetics: why does it seem so central for us as a species to care so much about aesthetic qualities. To put it in the words of evolutionary psychology and cognitive science, aesthetic judgements may operate at the level of virtual rather than real domains, which would make finding the core unity of an aesthetic mechanism difficult. Yet, next I proceed to argue that there is a way forward with maintaining that aesthetic judgement employs a group of more specialized skills.

According to Mercier and Sperber (2017): 81, representations of certain regularities in the world provide information about facts or goals. Modules that function for providing representations of representations are in turn called metarepresentational modules. They perform inferences from certain types of input: "The representation of a regularity doesn't do anything by itself, but it provides a premise that may be exploited by a variety of inferential procedures. A dedicated procedure does something: given an appropriate input, it produces an inferential output» (Mercier, Sperber [2017]: 87).

Metarepresentational modules are virtually domain-general because inferences can be about anything. This fits well with the case of aesthetics, where judgements vary from artifacts to nature, from the sense of the everyday to tact in human communications. Most often, inferences concern classifications (Mercier, Sperber [2017]: 91-93). Here, respectively, inferring aesthetic qualities are the focus.

Another notion about metarepresentational modules that fits well with aesthetics is that metarepresentational modules are not about the world in general but have smaller real domains in the case of aesthetics, aesthetic qualities. Aesthetic judgement feeds on aesthetic qualities that can be seen as types of representations, by defini- tion, containing meaning (for representations, see Mercier, Sperber [2017]: 92-93).

I suggest that aesthetic judgements can be seen as a way of intuitive inference in the same way that Mercier and Sperber see reasoning, namely, as another metarepresentational module (90). Mercier and Sperber's argumentation describes the metarepresentational module at work by clarifying the relationship between intuitions of explanations and the things being explained:

1. Our intuitions about good and bad explanations are not the same as our intuitions about the things explained.

2. Our intuitions about explanations exploit properties such as cogency, generality, or coherence that are properties of the explanations themselves and not of things explained.

3. Our intuitions about explanations (which make us prefer good explanations) is nevertheless a major source of insight about the things explained. (103).

I analogically combine this model, which illustrates metarepresentational modules performing inferences, with theories on aesthetic value, or what Fabian Dorsch calls «a standard picture» (Dorsch [2014]: 77) ${ }^{15}$. It means a view that differentiates between nonaesthetic features or lower-aesthetic qualities (such as color) and aesthetic qualities (such as beauty), relating to each other so that the former define the latter (see, for example, Sibley [1965]: 137-139; Levinson [1996]: $6)^{16}$. Treating forming aesthetic judgements as a

${ }^{15}$ «According to a standard picture, aesthetic values are realized by aesthetic qualities, which are again realized by non-aesthetic properties (see, e.g. Sibley [1965/2001] and [1959/2001]; Budd [1999]; Zangwill [2001])». Rather than tripartite categorization, I only use a two-step one, as noted above.

${ }^{16}$ I speak about lower-level aesthetic properties rather than nonaesthetic properties for the following reason. In contrast with Jerrold Levinson, Robert Stecker thinks aesthetic quality stems from lower-level aesthetic properties directly (for example, in the case of appreciating a sunset; see Stecker [2019]: 24). Stephen Davies would agree (Davies [2012]: chapter 1). This does not need to be a problem here, because even when «low-level perceptual features» constitute aesthetic qualities, aesthetic infer- 
metarepresentational module is not saying that aesthetic judgements go back to specific preconditions of the object but only that they - as perceived by the individual at a certain place and time - are used as grounds for aesthetic judgements. In other words, I am talking about aesthetic sensibility understood in the way John Bender proposes - as the ability to «identify certain features, properties, or relations of a work as being aesthetically significant, i.e., as either being valuemaking or value-lowering» - as a metarepresentational module (see Bender [2001]: 74).

Finally, relating the philosophical argumentation to forming a representation of a representation proceeds as follows:

1. Our intuitions about good or bad explications (about lower-level aesthetic properties) are not the same as our intuitions about the lower-level aesthetic properties.

2. Our intuitions about aesthetic qualities exploit lower-level aesthetic properties - and in the case of aesthetic appreciation of systems, knowledge - that need not match aesthetic qualities: according to aesthetic holism, depending on the instance, the same lowerlevel aesthetic property may indicate either aesthetic quality or the lack of it.

3. Our intuitions about the lower-level aesthetic properties are nevertheless a major source of insight about aesthetic quality.

Another way to conceptualize the aesthetic metarepresentational module that performs aesthetic inferences is to look at a case of aesthetic judgement. When I form the judgement «this rose is beautiful», I derive it with the help of oth-

ence is at play. We do not merely compute and register features but process them as aesthetic qualities, although they could also be treated as mere classificatory perceptual qualities. It is important to note that my aim is not to divorce aesthetic judgements from direct sensory experiences. Quite the contrary, inference comes with perception; we cannot help it (for inference in perception in more detail, see Mercier, Sperber [2017]: 57-60). Inferential processes vary in how fast they are and how much effort they require (59). Aesthetic judgements, therefore, need not be explicitly formed in order to be inferences. er modules, such as smell, perceiving symmetry and color, and feeling smoothness and softness by touch. The actual normative aesthetic judgement stands for the «meta-level» of this process revolving around classification. Making the inference is most often, if not always, largely intuitive, meaning that we cannot access the exact principles of the process (Dorsch [2014]: 83-84). Quoting Merlin Donald (2001): 178: "There is simply no direct awareness of the brain's activity and no possibility of achieving it. Brain activity is the end of the line. It is the source, never the object, of direct experience» ${ }^{17}$.

Treating forming aesthetic judgements as a metarepresentational module means giving up aesthetic empiricism. Aesthetic empiricism holds, Dorsch (2014: 75) points out, «that empirical evidence may - and often does - suffice to provide defeasible justification for our first or higher-order aesthetic judgements", whereas I claim that the process involves meta-level inference that is not totally reducible to modules such as perceiving symmetry. I am thus closer to aesthetic rationalism, according to which perceiving aesthetic properties requires cognitive inference - or, in other words, processing empirical features instead of only registering them (Dorsch [2014]: 78) ${ }^{18}$. The ways in which metarepresentational modules work describes this intuitive inferential procedure and thus offers support for aesthetic rationalism.

To recap, the processing system at work in aesthetic judgements may be a metarepresentational module as a functional part of the ensemble of other metarepresentational modules or it may

\footnotetext{
${ }^{17}$ Mercier and Sperber note the same issue and add that it is a common illusion to assume that the process of inference is directly available to the subject. This is the very reason why empirical methods defend their ground - although not overriding the philosophical approach in aesthetics (Mercier, Sperber [2017]: 59, 115).

18 Dorsch proceeds to take a normative stand on «the best method for the recognition of many aesthetic qualities, and more or less all aesthetic values» from the viewpoint of aesthetic rationalism (Dorsch [2014]: 96). I do not espouse this particular statement, since the issue is beyond the scope of this article.
} 
consist of several metarepresentational modules that activate according to different stimuli in different cases of aesthetic judgement (for example, when experiencing music on one hand and tact on the other). Metarepresentational modules have large, even general, virtual domains whose real domains are smaller than what has been anticipated in evolutionary aesthetics focusing on studying aesthetic judgements as instincts, not mechanisms (for virtual domain-generality, see Mercier, Sperber [2017]: 104-105). The contribution of all of this for evolutionary aesthetics is that hence it is possible to maintain the idea of a domain-general «aesthetic mechanism» ${ }^{19}$ producing multi-modal and elastic aesthetic schemes without direct fitness-increasing functions and base this understanding on evolutionary psychology, that is, combining cultural evolution with modularity.

Lastly, I sketch some future directions in coevolutionary aesthetics and draw an analogy to reading as being modular but not a genetic evolutionary adaptation. Aesthetic judgement, too, may belong to modules produced by practice: it could have developed either so that habit and experience shape it to appear as having specialized from some other evolved system or so that there is developmental specialization into different modules phenotypically, although it still utilizes the same evolved system (for reading capability, see Barrett, Kurzban [2006]: 639). It is an important topic of further investigation if the mechanism of aesthetic judgement is, like that of reading, not a cognitive

\footnotetext{
${ }^{19}$ Desideri describes this mechanism: «[b]ecause of its epigenetic nature, the mechanism by which an aesthetic mind arises is conceivable as an operative sub-structure capable of producing schemes (patterns) that have neither the fluidity of the emotional-affective schemes nor the articulation in specific categorical domains that characterizes the cognitive schemes. Compared to the affective and cognitive schemes, the aesthetic ones are elastic, multimodal, and lacking a specific domain. Their internal differentiation is based on the relevance and the role assumed in them, jointly or separately, by each of the four moments (mimesis, seeking, preference, and play). Thanks to its internal differentiation, the aesthetic mechanism holds degrees of freedom relative to both its functioning and development» (Desideri [2015]: 36-37).
}

instinct but a cognitive gadget shaped by a culturally inherited and individually unique route construction (Heyes [2018]: 19-20). How aesthetic judgements develop in the course of coevolution with aesthetic objects indicates that the capacity for aesthetic judgement may be a product of cultural evolution. This is what I think Portera is after when claiming that there is no innate psychological module for the aesthetic capacity (see Portera [2020]: 313). The argument is backed up by demonstrating the wealth rather than the poverty of stimulus in acquiring the mechanism from the environment - a case she advocates herself. Like the rest of metacognition, it is possible this mechanism is not only culturally transmitted but also even refined for the purpose by cultural rather than natural selection (Heyes, Bang, Shea, Frith, Fleming [2020]: 351-352).

Regarding reasoning, the module does not motivate but only explains and justifies intuitions (Mercier, Sperber [2017]: 112). Consequently, I suggest that the aesthetic module does not work to make us experience aesthetically - and here I distinctly part from the majority of earlier evolutionary aesthetics - but only to construct aesthetic judgements. This being the case, the focal point for future research could be in aesthetic judgement as a cognitive module, not as a genetic adaptation. Some of the recent neuroaesthetics research echoes Kant in hypothesizing that an aesthetic experience activates systems of «liking» instead of "wanting» (Chatterjee, Vartanian [2014]: 372 ${ }^{20}$. The consequence and product of aesthetic experience should be differentiated so that the latter only concerns the stimulus perception instead of gravitating toward pleasant stimuli:

20 This is an interesting opening in empirical aesthetics, because the roots of naturalism and hence also evolutionary aesthetics have been in opposing the Kantian idea of aesthetic engagement for its own sake, separate from other purposes - and some philosophical aesthetics researchers have had concerns about applying empirical knowledge to aesthetics because they find it to be discarding the independence of the aesthetic. For an article discussing the Kantian autonomy of aesthetic judgements and empirical aesthetics, see Schellekens (2011). 
"[...]modulation of neural activity in reward, perceptual and motor areas during aesthetic experience and positive attitudes to stimuli may not so much be segregated in their neuroanatomical organization, but rather in their temporal dynamics and ultimate outcome» (Kirsch, Urgesi, Cross [2016]: 65).

However, an explanation about how the module for aesthetic judgement evolves would only follow the clarification of what the capacity for aesthetic judgement is, rather than assuming it is a genetic adaptation for favoring positive stimuli and avoiding the negative. Cecilia Heyes lists that a selectionist theory for a cognitive mechanism needs a hypothesis on: «(1) the entities that are evolving; (2) the routes of their inheritance; and (3) the kinds of social learning that provide an inheritance system» (Heyes [2018]: 37). I have only touched upon the first and glanced at the second item. Even so, the article at hand has laid out a reason to believe the capacity for aesthetic judgement is a promising candidate for being a) a cognitive mechanism with b) a selectionist history.

\section{CONCLUSION}

This article is part of the ongoing paradigm shift in evolutionary aesthetics: moving away from the traditional research questions, such as whether aesthetic sensibility has been preserved in natural selection, or what function what we see as artistic behavior has served in the Pleistocene. As answers to these questions have become more and more agnostic, new research questions emerge. They concern mechanisms alongside with skills ${ }^{21}$. Evolutionary aesthetics should not ask whether we make aesthetic judgements because of evolution but what evolutionary factors influence aesthetic inference, the judgements we make about aesthetic qualities. For some behavioral trait to evolve, it

\footnotetext{
${ }^{21}$ Heyes uses a metaphor of mills for mechanisms and grist for skills - including ideas and behaviors - and claims that adding cultural evolution to evolutionary psychology makes it more apparent that some mechanisms, too, are inherited socially (see Heyes [2018]: 44).
}

does not matter whether it is genetically inherited or not. Making aesthetic judgements entails both our cognitive systems being at work and them working in a certain kind of an environment, including that of the body itself and our previous experiences.

I have argued that speaking of aesthetic inference as an evolutionary entity is problematic. The scope of research questions in evolutionary aesthetics widens as what was once known as aesthetic instinct becomes an aesthetic niche (Menary [2014]; Richards [2019]; Portera [2020]). I have claimed that the idea of totally unmodular evolutionary aesthetics is an oxymoron, and the juxtaposition of coevolutionary aesthetics (that emphasizes plasticity and the role of environment in the development of aesthetic inference) versus evolutionary psychology (that relies on looking at «innate» modules) is disproportional. As I have shown, it is possible to treat aesthetic inference as a metarepresentational module without seeing it as a coherent mechanism or having direct fitnessincreasing functions. This is a new - and I hope - consolidating contribution to an emerging division that is not so much due to actual disagreement but different, or at least blurred, uses of the concept of «module». If this gap can be bridged - and I think it can - the best parts of both approaches can be picked and combined: evolutionary psychology offers insight into cognitive systems and, more specifically, the evolutionary adaptations, such as plasticity, that are typical for humans. Coevolutionary aesthetics, in turn, offers means to include more comprehensively than what has been previously done in evolutionary aesthetics ever-changing factors that characterize aesthetic inference and how it is inherited.

In short, contrary to what David Fishelov among others claims, the common ground of all evolutionary approaches to art research is not an assumption that art or a certain art form would be adaptive (see Fishelov [2017]: 274). I propose that the common ground is - as surprising as it might seem considering the impending partition between evolutionary psychology and coevolutionary aesthetics - modularity. Acknowledging 
that modularity of mind and cultural evolution are complementary brings evolutionary aesthetics closer to both contemporary, or cultural, evolutionary psychology and humanities. Despite the fact that openings have been made, it still remains to be studied more carefully what skills the capacity for aesthetic judgement exploit and link together, what its developmental process is, and how cultural - or social - learning influences the development and functioning of the mechanism ${ }^{22}$.

\section{REFERENCES}

Barrett, H., Kurzban, R, 2006: Modularity in Cognition: Framing the Debate, "Psychological review" 113 (3), pp. 628-647.

Bartalesi, L., 2019: From the aesthetic mind to the human cultures: Towards an anthropology of aesthetic, "Aisthesis" 12 (1), pp. 15-26.

Bender, J.W., 2001: Sensitivity, Sensibility, and Aesthetic Realism, "The Journal of Aesthetics and Art Criticism” 59 (1), pp. 73-83.

Breitenbach, A., 2020: One Imagination in Experiences of Beauty and Achievements of Understanding, "The British Journal of Aesthetics" 60 (1), pp. 71-88.

Carroll, J., 2012: An Open Letter to Jonathan Kramnick, "Critical Inquiry" 38 (2), pp. 405410.

\footnotetext{
${ }^{22}$ I am indebted to Arto Haapala, Petri Ylikoski, Emma Vitikainen; Alexis Makin, and others at the Visual Perception (Bertamini) Lab at the University of Liverpool; Minna Lyons, Sanna Lehtinen, and Hanne Appelqvist for their feedback, discussion, and, not least, encouragement, which have been pivotal for creating this article. I would also like to thank everyone at the University of Helsinki Aesthetics researcher seminar; the Nordic Society for Aesthetics 2021 Conference, especially Oiva Kuisma; the European Society for Aesthetics 2021 Conference; and the International Society for Human Ethology 2021 Conference; as well as the anonymous reviewer for their invaluable insight. I am grateful for Albion Butters and Bradley Reynolds for editing my English grammar. Finally yet importantly, I am thankful to the Finnish Academy of Science and Letters who funded me during work on this article.
}

Carruthers, P., 2006: The Architecture of the Mind, Oxford University Press, Oxford.

Chatterjee, A., 2014: The Aesthetic Brain: How We Evolved to Desire Beauty and Enjoy Art, Oxford University Press, Oxford.

Chatterjee, A., Vartanian, O., 2014: Neuroaesthetics, "Trends in cognitive sciences" 18 (7), pp. 370-375.

Clune, J., Mouret, J-B., Lipson, H., 2013: The Evolutionary Origins of Modularity, "Proceedings of the Royal Society. B, Biological sciences" 280 (1755), pp. 1-9.

Davies, S., 2012: The Artful Species: Aesthetics, Art, and Evolution, Oxford University Press, Oxford, 2013.

Davies, S., 2020: Adornment: What Self-decoration Tells Us about Who We Are, Bloomsbury, London.

Deacon, T., 2006: The Aesthetic Faculty, in Turner, M. (ed.), The Artful Mind: Cognitive Science and the Riddle of Human Creativity, Oxford University Press, Oxford, pp. 21-53.

Desideri, F., 2013: On the Epigenesis of the Aesthetic Mind. The Sense of Beauty from Survival to Supervenience, "Rivista di estetica" 54 (3), pp. 63-82.

Desideri, F, 2015: Epigenesis and Coherence of the Aesthetic Mechanism, "Aisthesis. Pratiche, linguaggi e saperi dell'estetico" 8 (1), pp. 25-40.

Dissanayake, E., 2018: Ancestral Minds and the Spectrum of Symbol, in Malotki, E., Dissanayake, E. (eds.), Early Rock Art of the American West: The Geometric Enigma, University of Washington Press, Seattle, pp. 91-129.

Donald, M., 2001: A Mind so Rare: the Evolution of Human Consciousness, W.W. Norton \& Company, New York.

Dorsch, F., 2014: The Limits of Aesthetic Empiricism, in Currie, G., Kieran, M., Meskin, A., Robson, J. (eds.), Aesthetics and the Sciences of Mind, Oxford University Press, Oxford, pp. 75-100.

Dutton, D. 2009: The Art Instinct: Beauty, Pleasure, \& Human Evolution, Oxford University Press, Oxford.

Fishelov, D., 2017: Evolution and Literary Studies: Time to Evolve, "Philosophy and Literature" 41 (2), pp. 272-289. 
Heyes, C., 2018: Cognitive Gadgets: The Cultural Evolution of Thinking, Harvard University Press, Cambridge, MA.

Heyes, C., Bang, D., Shea, N., Frith, C.D., Fleming, S.M., 2020: Knowing Ourselves Together: The Cultural Origins of Metacognition, "Trends in Cognitive Sciences” 24(5), pp. 349-362.

Keller, E.F., 2010: The Mirage of a Space between Nature and Nurture, Duke University Press, Durham \& London.

Kiianlinna, O., 2018: Valinnasta välittymiseen. Voidaanko kulttuurievoluution ajatusta soveltaa evoluutioestetiikkaan?, Master's thesis, University of Helsinki.

Kirsch, L.P., Urgesi, C., Cross, E.S., 2016: Shaping and Reshaping the Aesthetic Brain: Emerging Perspectives on the Neurobiology of Embodied Aesthetics, "Neuroscience and Biobehavioral Reviews" 62, pp. 56-68.

Kramnick, J., 2011: Against Literary Darwinism, "Critical Inquiry" 37 (2), pp. 315-347.

Levinson, J., 1996: The Pleasures of Aesthetics, Cornell University Press, Ithaca, NY.

Malotki, E., Dissanayake, E. (eds.), 2018: Early Rock Art of the American West: The Geometric Enigma, University of Washington Press, Seattle.

Menary, R., 2014: The Aesthetic Niche, "The British Journal of Aesthetics" 54 (4), pp. 471-475.

Mercier, H., Sperber, D., 2017: The Enigma of Reason: a New Theory of Human Understanding, Penguin Books, London, 2018.

Pitkänen, R., 2009: Miten evoluutio selittää esteettisiä mieltymyksiä, "Tieteessä tapahtuu" 27 (2), pp. 15-22.

Portera, M., Mandrioli. M., 2015: Tastes of the Parents: Epigenetics and its Role in Evolutionary Aesthetics, "Evental Aesthetics" 4 (2), pp. 46-76.

Portera, M., Bartalesi, L., 2016: Aesthetic Preferences: An Evolutionary Approach, in Serrelli, E., Panebianco, F. (eds.), Understanding Cultural Traits: A Multidisciplinary Perspective on Cultural Diversity, Springer, Berlin, pp. 375-388.

Portera, M., 2020: Babies Rule! Niches, Scaffoldings, and the Development of an Aesthetic Capacity in Humans, "The British Journal of Aesthetics" 60 (3), pp. 299-314.

Richards, R., 2019: The Biology of Art (Elements in the Philosophy of Biology), Cambridge University Press, Cambridge.

Robbins, P., 2017: Modularity of Mind, in Zalta, E.N. (ed.), The Stanford Encyclopedia of Philosophy, Winter Edition, https://plato.stanford. edu/archives/win2017/entries/modularitymind/.

Schellekens, E., 2011: Experiencing the Aesthetic: Kantian Autonomy or Evolutionary Biology?, in Schellekens, E., Goldie, P. (eds.), The Aesthetic Mind: Philosophy \& Psychology, Oxford University Press, Oxford, chapter 12.

Seghers, E., 2014: Cross-Species Comparison in the Evolutionary Study of Art: A Cognitive Approach to the Ape Art Debate, "Review of General Psychology" 18 (4), pp. 263-272.

Seghers, E., 2015a: The Artful Mind: A Critical Review of the Evolutionary Psychological Study of Art, "The British Journal of Aesthetics" 55 (2), pp. 225-248.

Seghers E., 2015b: Of Darwin and Other Demons: the Evolutionary Turn in Aesthetics, "KulturaSpołeczeństwo-Edukacja” 2 (8), pp. 73-90.

Sibley, F., 1965: Aesthetic and Nonaesthetic, "The Philosophical Review" 74 (2), pp. 135-159.

Skov, M., Nadal, M., 2019: The Nature of Perception and Emotion in Aesthetic Appreciation: A Response to Makin's Challenge to Empirical Aesthetics, "Psychology of Aesthetics, Creativity, and the Arts" 15 (3), pp. 470-483.

Sperber, D., 2001: An Evolutionary Perspective on Testimony and Argumentation, "Philosophical Topics" 29 (1\&2), pp. 401-413.

Stecker, R., 2019: Intersections of Value: Art, Nature, and the Everyday, Oxford University Press, Oxford.

Verpooten, J., Dewitte, S., 2017: The Conundrum of Modern Art: Prestige-Driven Coevolutionary Aesthetics Trumps Evolutionary Aesthetics among Art Experts, "Human Nature" 28 (1), pp. 16-38. 